\title{
O RIO GRANDE DO NORTE COMO CONTEÚDO NA DISCIPLINA DE GEOGRAFIA NO ENSINO MÉDIO
}

\section{RIO GRANDE DO NORTE AS CONTENT IN THE GEOGRAPHY DISCIPLINE IN HIGH SCHOOL}

\author{
SOUSA, Patrícia Tâmara da Silva ${ }^{1}$ \\ SILVA, Cícero Nilton Moreira da²
}

\begin{abstract}
RESUMO
O presente artigo versa sobre os conteúdos de Geografia no Ensino Médio, e apresenta um recorte da dissertação "Geografia escolar: o Rio Grande do Norte como conteúdo no Ensino Médio", defendida junto ao Programa de Pós-Graduação em Ensino (PPGE) pela Universidade do Estado do Rio Grande do Norte (UERN). Discutimos sobre a possibilidade e necessidade de conceber o Rio Grande do Norte como conteúdo geográfico. Buscamos analisar discussões teóricas e concepções de ensino que situem o RN no cerne das abordagens dos conteúdos de Geografia em 02 (duas) escolas públicas estaduais de Ensino Médio, no município de Pau dos Ferros/RN. Para tanto, realizamos uma revisão bibliográfica, estudo documental e entrevista semiestruturada com os professores de Geografia. A pesquisa apontou que as abordagens sobre o RN na disciplina de Geografia são pouco visíveis, exceto as aulas de campo, que trouxeram visibilidade e valorização aos conteúdos acerca da Geografia norte-rio-grandense.
\end{abstract}

Palavras-Chave: Geografia; Conteúdo; Rio Grande do Norte.

\section{ABSTRACT}

This article deals with the contents of Geography in High School, and presents a clipping of the dissertation "School geography: Rio Grande do Norte as content in Secondary School", defended with the Postgraduate Program in Education (PPGE) by the State University of Rio Grande do Norte (UERN). We discussed the possibility and necessity of designing Rio Grande do Norte as geographic content. We seek to analyze theoretical discussion sand conceptions of teaching that locate the RN at the core of the approaches of Geography contents in 02 (two) state public high schools in the municipality of Pau dos Ferros/RN. For that, we carried out a bibliographical review, a documentary study and a semi-structured interview with the teachers of Geography. The research pointed out that the approaches on the RN in the discipline of

\footnotetext{
${ }^{1}$ Universidade do Estado do Rio Grande do Norte (UERN). Pau dos Ferros, RN, Brasil. ORCID: https://orcid.org/0000-0002-1598-364X e-mail: patricia tamara@outlook.com

2 Universidade do Estado do Rio Grande do Norte (UERN). Pau dos Ferros, RN, Brasil. ORCID: http://orcid.org/0000-0001-6773-7451 e-mail: ciceronilton@uern.br
} 
DOI: $10.12957 / \mathrm{e}-\mathrm{mosaicos} .2020 .46572$

Geography are not very visible, except the field classes that brought visibility and valorization to the contents about the Geography of Rio Grande do Norte.

KeYWORDS: Geography; Content; Rio Grande do Norte.

\section{INTRODUÇÃO}

Este artigo traz um recorte de uma dissertação que tem a finalidade de estudar a o Rio Grande do Norte como conteúdo no Ensino Médio, resultante de uma pesquisa realizada entre os anos de 2016 a 2017, em 02 (duas) escolas públicas de Ensino Médio do Município de Pau dos Ferros/RN. Cujo objetivo geral foi analisar discussões teóricas e concepções de ensino, que situassem o Rio Grande do Norte no cerne dos conteúdos da Geografia escolar no Ensino Médio.

Nesse sentido, ressaltamos a problemática da abordagem de uma Geografia voltada a pensar a organização do espaço sob a escala das unidades federativas brasileiras. No caso da pesquisa realizada, destacamos o temário da leitura geográfica a respeito do Rio Grande do Norte.

Assim, como resultado de uma produção social, o Rio Grande do Norte é também objeto de estudo da Geografia, o que expressa a necessidade de estar vinculado aos demais conteúdos que formam o currículo da disciplina de Geografia no Ensino Médio. De modo que os alunos possam conhecê-lo. $\mathrm{E}$, além disso, consigam perceber-se como agentes de transformação do espaço norte-rio-grandense. Compreendendo que suas ações implicam também na produção desse espaço.

Tratamos da necessidade e possibilidade de um ensino que contemple a compreensão dos aspectos geográficos que configuram o território potiguar. Isso porque, entendemos que a Geografia, tendo como objeto de estudo o espaço geográfico, precisa investir no seu potencial explicativo para tornar possível a apreensão sobre a realidade, e porque não dizer, entender a realidade territorial na qual os alunos estão inseridos. Isso favorece o "valor educacional" da Geografia, assim como salienta Oliva (2006).

Dessa forma, para realização da pesquisa delimitamos o Alto Oeste Potiguar, mais precisamente o município de Pau dos Ferros/RN para realização deste estudo. 0 Município possui um quadro representativo de escolas de Ensino Médio e professores de Geografia, o que denota uma amostragem significativa para a pesquisa: 02 (duas) escolas estaduais públicas de Ensino Médio e 03 (três) professores de Geografia.

No quadro 01 são apresentados os dados da identificação e aspectos da experiência docente dos professores-sujeitos da pesquisa. 
DOI: $10.12957 / \mathrm{e}-\mathrm{mosaicos} .2020 .46572$

Quadro 01: Perfil dos professores entrevistados

\begin{tabular}{|c|c|c|c|c|}
\hline Professor & Formação/Ano/IES & Titulação & $\begin{array}{c}\text { IE } \\
\text { vinculada }\end{array}$ & $\begin{array}{c}\text { Regime de } \\
\text { trabalho/Tempo de } \\
\text { docência(em anos) }\end{array}$ \\
\hline P 1 & Geografia/2010/UERN & Especialista & Escola 1 & $30 / 05$ \\
\hline P 2 & Geografia/2005/UERN & Especialista & Escola 2 & $30 / 08$ \\
\hline P 3 & Geografia/2006/UERN & Especialista & Escola 2 & $30 / 10$ \\
\hline
\end{tabular}

Fonte: Informações coletadas em dados da pesquisa de campo, 2017.

Para preservar a identidade e a integridade dos sujeitos envolvidos iremos identificá-los como professores P1, P2 e P3, assim como as escolas serão representadas por Escola 1 e Escola 2.

\section{O Rio GRANDE do NORTE COMO CONTEÚDo}

Neste trabalho desafiamo-nos a discutir sobre o Rio Grande do Norte enquanto conteúdo no ensino de Geografia, pois, acreditamos que o estudo desta temática seja de fundamental importância para compreensão do espaço geográfico. Os conteúdos de Geografia podem ser entendidos como um importante instrumento de apropriação e construção do conhecimento, por meio do qual os alunos podem compreender os espaços vividos, ou até mesmo espaços desconhecidos. Eles favorecem o trabalho docente a partir dos objetivos que se desejam alcançar com o ensino dos mesmos. São saberes que foram sistematizados ao longo dos anos e que, transpostos em forma de conteúdo, revelam a formação da sociedade, com seus aspectos naturais e sociais.

Embora tenhamos à disposição uma diversidade de obras e trabalhos acadêmicos que versam sobre os diversos fenômenos geográficos do Rio Grande do Norte, são raras as bibliografias que, em particular, tratam do ensino deste como conteúdo escolar. Dessa forma, consideramos que este seja um trabalho desafiador, sobretudo, mediante às novas conjunturas que se formam constantemente na sociedade, e em especial no contexto educacional.

De acordo com Felipe e Rodriguez (2009, p. 1), o conhecimento é o grande fator de produção e desenvolvimento no mundo atual, por isso, torna-se importante reconhecer que o conhecimento é imprescindível para a compreensão de uma dada realidade. Assim, se o professor contribuir para desenvolver potencialidades no aluno, este vai perceber que o conhecimento também é poder; "serve para dominar ou combater a dominação, e que o educando pode e deve tornar-se co-autor do saber" (VESENTINI, 2008, p. 15). 
DOI: $10.12957 /$ e-mosaicos.2020.46572

Dada a importância do conhecimento, elucidamos que é necessário conhecer mais e melhor o território potiguar; sua história, seus aspectos físicos e ambientais, os eixos institucionais e sociais, economia, cultura, política e etc. $E$, deste modo, compreender as relações dinâmicas que configuram o território, e que, por conseguinte, (re)produzem o espaço geográfico.

No Rio Grande do Norte, o Professor Dr. José Lacerda Alves Felipe, destaca-se por sua grande contribuição à Geografia Potiguar, por meio da publicação de artigos, livros, capítulos de livros, Manual de professor e Atlas escolar, com importantes abordagens sobre a Geografia do RN. Com relação à elaboração de Atlas escolares do RN, ainda podemos mencionar Edílson Alves de Carvalho e Aristotelina Pereira Barreto Rocha, que elaboraram alguns atlas e livros em conjunto com José Lacerda, quais sejam: Atlas do Rio Grande do Norte: espaço geo-histórico e cultural (2011), Atlas Escolar do Rio Grande do Norte (2011), Economia do Rio Grande do Norte (2011), Atlas do Rio Grande do Norte - espaço geo-histórico e cultural (2004).

Consideramos importante dar ênfase aos Atlas escolares, pois, acreditamos que este recurso didático está mais próximo da realidade escolar. Os Atlas escolares aos quais nos retratamos, foram publicados pela Editora Granfset, que produziu atlas para os nove estados nordestinos, com o objetivo de "auxiliar o ensino e a pesquisa da geografia, nesse contexto de acelerada integração global" (FELIPE; RODRIGUEZ, 2009, p. 1).

Sobre a importância desses atlas, Felipe e Rodriguez (2009, p. 4-6) enfatizam:

Os modernos atlas escolares estaduais permitem comparações entre os espaços estudados, vez que, através das abordagens culturais e geo-históricas, o leitor se percebe integrado no seu espaço mais próximo (município, estado) e passa a analisar com profundidade seu espaço percebido e vivido, englobando as relações locais contextualizadas e ressignificadas por outras elaboradas.

Seria importante também que no ensino de Geografia houvesse uma contextualização dos fatos e fenômenos que ocorrem no espaço, para que ocorresse a inclusão de conteúdos sobre a Geografia dos estados no currículo escolar. É fato que não existe na grade curricular do Ensino Médio uma disciplina que trate das peculiaridades de cada Estado, no entanto, isso não significa que estes conhecimentos não sejam relevantes à formação pessoal, intelectual e profissional do educando.

Fazendo uma leitura da Constituição do Estado do Rio Grande do Norte (1989), encontramos no $\S 2^{\circ}$ do Art.137, uma abertura a introdução do RN como conteúdo entre as disciplinas oferecidas pelo currículo escolar. "As escolas públicas, de primeiro e segundo graus, incluem entre as disciplinas oferecidas o estudo da cultura norte-riograndense, envolvendo noções básicas da literatura, artes plásticas e folclore do Estado" (RIO GRANDE DO NORTE, 1989, p. 47). 
DOI: $10.12957 /$ e-mosaicos.2020.46572

Entretanto, como podemos observar, essa abordagem é muito limitada, pois, enfatiza apenas os aspectos culturais do RN, deixando a desejar um estudo mais preciso e completo sobre o Estado. No entanto, é preciso ressaltar que embora os demais aspectos da Geografia do Rio Grande do Norte não estejam contemplados na Constituição, não significa que não mereçam ser estudados. Em razão de que todos os fatos e fenômenos geográficos que configuram o RN contribuem para a formação do seu espaço.

Assim, para pensar e decidir sobre os conteúdos escolares é primordial o planejamento e o estabelecimento dos objetivos que se desejam alcançar com o ensino destes. Como salienta Oliveira (2008, p. 142), "cabe a Geografia levar a compreender o espaço produzido pela sociedade em que vivemos hoje, suas desigualdades e contradições, as relações de produção que nela se desenvolvem e a apropriação que a sociedade faz da natureza".

Desse modo, o Estado do Rio Grande do Norte, constituindo uma unidade federativa, se caracteriza como um agente de produção e transformação do espaço. Ou seja, o RN é reflexo de um espaço materializado a partir das relações do homem com a natureza ao longo da história, e assim, cabe ser estudado e compreendido.

\section{A Geografia do Rio Grande do Norte: uma abordagem presente no Ensino MÉDIO?}

Ao iniciar um ano letivo, os professores se veem frente ao desafio de selecionar os conteúdos a serem estudados. A seleção e organização dos conteúdos é uma responsabilidade muito grande, por isso buscamos analisar inicialmente qual a proposta dos PPP das escolas pesquisadas quanto ao planejamento escolar. A Escola 1 apresenta uma rotina pedagógica demandada por orientações indicadas para os momentos de planejamento coletivo: semana pedagógica, escolha reflexiva dos objetivos, organização e seleção dos conteúdos e organização dos tempos, espaços e recursos didáticos.

A semana pedagógica acontece no início do ano letivo e tem como objetivo avaliar o trabalho realizado no ano anterior e, a partir dos resultados, (re)planejar ações na perspectiva de rever as fragilidades e fortalecer as potencialidades. A escolha reflexiva dos objetivos é pautada na importância do planejamento das atividades escolares, que pressupõe um entendimento anterior sobre o que se pretende alcançar com o ensino. Na organização e seleção dos conteúdos, a escola compreende que os conteúdos acadêmicos são os saberes que os alunos devem construir e/ou reconstruir, ao longo de sua formação. Dessa forma, os conteúdos devem estar articulados com outros, de diferentes áreas. A organização dos tempos, espaços e recursos didáticos, implica nos resultados dos processos pedagógicos, pois são condições objetivas para a efetivação do trabalho docente. O tempo destinado às atividades acadêmicas é distribuído no calendário anual, em bimestres e dias letivos. 
DOI: $10.12957 /$ e-mosaicos.2020.46572

Na Escola 2 o planejamento escolar é realizado em consonância com as jornadas pedagógicas, que acontecem no início de cada semestre letivo, e prossegue de forma contínua durante todo ano escolar, de acordo com as necessidades e disponibilidade dos professores e equipe pedagógica.

De acordo com o PPP da Escola 2, a seleção dos conteúdos escolares deverá ter como referência a concepção que cada professor tem com o ensino e sua função social. Levando em consideração a organização curricular do ensino médio, estabelecida pelas Diretrizes Curriculares Nacionais (DCN), que compreendem uma base nacional comum e uma parte diversificada, que se ajusta às peculiaridades regionais e locais da sociedade e da cultura, da economia e comunidade escolar e se articulam às áreas do conhecimento: Linguagem, Matemática, Ciências Naturais e Ciências Humanas.

Conforme consta nos PPP, existe um planejamento coletivo nas escolas. Os conteúdos escolares são orientados pelas diretrizes que regulamentam o Ensino Médio e auxiliam o professor a decidir sobre o que os alunos deverão estudar. Para isso, o professor precisa ter clareza de quais objetivos deseja alcançar, e qual o impacto que esses conteúdos farão na vida dos estudantes. No Quadro 02, esquematizamos como é feita a seleção e organização dos conteúdos pelos professores sujeitos da pesquisa.

Quadro 02: A organização dos conteúdos da disciplina de Geografia

\begin{tabular}{|l|l|}
\hline Professor & \multicolumn{1}{|c|}{ Organização dos conteúdos } \\
\hline P1 & $\begin{array}{l}\text { Eu procuro organizar de acordo com o livro didático, suprindo as necessidades, } \\
\text { quando eu vejo que o livro não retrata muito a realidade do aluno, então } \\
\text { trabalho com o conteúdo do livro didático, puxando para a realidade do aluno. } \\
\text { Por exemplo, trabalhando urbanização, trabalho o conteúdo do livro didático e } \\
\text { depois pesquiso sobre o processo de urbanização da cidade em que estamos } \\
\text { inseridos e trabalho em sala de aula a vivência do aluno. }\end{array}$ \\
\hline P 2 & $\begin{array}{l}\text { Eu pego o sumário do livro, dou uma olhada no livro todo, e divido os } \\
\text { conteúdos. Geralmente são 12 capítulos, eu divido nos 4 bimestres, [...] Mais } \\
\text { geralmente dar três capítulos por bimestre e daí eu sigo.[...] E aí eu vou } \\
\text { planejando minhas aulas de acordo com o livro. O livro é tipo o roteiro, eu sigo } \\
\text { o livro, mais também não me impede de eu trazer outras coisas para } \\
\text { complementar. }\end{array}$ \\
\hline $\begin{array}{l}\text { A questão da organização dos conteúdos, eu particularmente, sou metódico, } \\
\text { rigoroso. [...] A gente segue uma sequência dentro do planejamento, mais a } \\
\text { gente procura contextualizar. Por exemplo, nós estamos falando da primeira } \\
\text { fase do capitalismo, o capitalismo comercial, que alguns chamam de pré } \\
\text { capitalismo. Na sequência nós deveríamos falar no capitalismo industrial e suas } \\
\text { sub fases, mas, temos o cuidado de contextualizar, os dias de hoje com aqueles } \\
\text { dias do século XVI, então apesar da gente ter cuidado com a sequência lógica, } \\
\text { mas nós também temos o cuidado de contextualizar. }\end{array}$ \\
\hline
\end{tabular}

Fonte: Informações coletadas em dados da pesquisa de campo, 2017. 
DOI: $10.12957 / \mathrm{e}-\mathrm{mosaicos} .2020 .46572$

Como podemos observar, quando se refere à seleção e organização dos conteúdos escolares, o livro didático aparece como o principal instrumento de trabalho desses professores. Representa um recurso crucial ao processo educativo, constituindo a base referencial para a discussão dos conteúdos em sala de aula. Deste modo, os conteúdos de Geografia no Ensino Médio são selecionados e organizados segundo a determinação do livro didático, ou seja, primeiro se dá prioridade à sequência de conteúdos estruturados no livro e só a partir daí, caso o professor sinta necessidade, insere outros temas e discussões que estabeleçam conexão como temas e assuntos que estão no respectivo livro.

O livro didático é um material de apoio para o professor, direciona o currículo escolar e funciona como um suporte teórico para o aluno, apresentando diversas formas de linguagens. No entanto, o ensino não deve estar limitado apenas aos livros. É essencial que entendamos que quando nos limitamos aos livros, estamos, de certa forma, restringindo os alunos de tomar conhecimento de outros temas que também são importantes para construção da sua identidade, enquanto sujeitos sociais e partícipes da construção do espaço. Somos desafiados a tornar as coisas mais concretas, e dar sentido ao que os alunos estão estudando, procurando evitar o amontoado de informações superficiais e sem sentido, repassadas muitas vezes para os alunos através dos livros.

Compreendendo que o livro didático é a principal bibliografia utilizada pelos professores, e no geral os assuntos dos livros não abordam em específico a Geografia dos estados, julgamos necessário investigar se o RN é ausente nos conteúdos da Geografia escolar, assim como é nos livros didáticos. Para isso, questionamos os professores a fim de perceber se o território potiguar é concebido como conteúdo, e como fazem para abordá-lo. As respostas dos professores quanto a essa questão estão organizadas no Quadro 03.

Quadro 03: O Rio Grande do Norte como conteúdo na Geografia

\begin{tabular}{|l|l|l|}
\hline Professor & $\begin{array}{c}\text { Os professores concebem o RN } \\
\text { como conteúdo geográfico } \\
\text { escolar? }\end{array}$ & \multicolumn{1}{|c|}{ Como abordam? } \\
\hline P 1 & $\begin{array}{l}\text { Com certeza. Não adianta eu explicar } \\
\text { o global se não explicar o local. } \\
\text { Nossos alunos estão inseridos no Rio } \\
\text { Grande do Norte, então eles têm que } \\
\text { conhecer o Rio Grande do Norte e } \\
\text { comparar com a realidade do Brasil, } \\
\text { com a realidade de outros países. }\end{array}$ & $\begin{array}{l}\text { Primeiro eu explico o assunto que está } \\
\text { lá do livro didático. Pronto eu trabalhei } \\
\text { a região Nordeste, quando eu terminei } \\
\text { de trabalhar a região do Nordeste, eu } \\
\text { puxei pra o Rio Grande do Norte, a } \\
\text { questão da hidrografia, os aspectos } \\
\text { físicos, os aspectos populacionais e } \\
\text { sociais, sócio-econômicos culturais. }\end{array}$ \\
\hline
\end{tabular}


DOI: $10.12957 / \mathrm{e}-\mathrm{mosaicos} .2020 .46572$

\begin{tabular}{|c|c|c|}
\hline P 2 & $\begin{array}{l}\text { Com certeza. Porque eu acho } \\
\text { interessante que o aluno conheça seu } \\
\text { próprio estado, não ficar só aquela } \\
\text { coisa bitolada no Enem. Claro, é } \\
\text { importante, tem que estar preparado, } \\
\text { mais eu também acho importante de } \\
\text { saber sobre o lugar que eles moram, } \\
\text { que eles nasceram, o estado deles, as } \\
\text { riquezas, a economia. }\end{array}$ & $\begin{array}{l}\text { De acordo com os conteúdos que } \\
\text { estão sendo abordados no livro, vou } \\
\text { tentando trazer um pouco para a } \\
\text { realidade deles, através de exemplos. } \\
\text { Buscando sempre fazer uma ligação } \\
\text { com as questões globais e locais e } \\
\text { consequentemente sobre o RN. }\end{array}$ \\
\hline P 3 & $\begin{array}{l}\text { Olha, assim, a sua pergunta é } \\
\text { interessante e me fez refletir bastante } \\
\text { sobre ela agora. Porque geralmente } \\
\text { nós estudamos a Geografia global e a } \\
\text { Geografia nacional e às vezes até a } \\
\text { Geografia regional. Mas a Geografia } \\
\text { da cidade, do município, do estado em } \\
\text { si raramente a gente estuda, então é } \\
\text { um ponto importante a ser tocado e } \\
\text { que precisa no mínimo de uma boa } \\
\text { reflexão. }\end{array}$ & $\begin{array}{l}\text { A gente discute mais nos momentos } \\
\text { de contextualização, por exemplo, a } \\
\text { gente está discutindo a questão da } \\
\text { industrialização, a gente vai e } \\
\text { contextualiza com as indústrias do RN. } \\
\text { Mais o foco central não é a Geografia } \\
\text { do RN, ela é usada apenas como mero } \\
\text { complemento. }\end{array}$ \\
\hline
\end{tabular}

Fonte: Informações coletadas em dados da pesquisa de campo, 2017.

P1 e P2 afirmaram conceber o RN como conteúdo. No entanto, notamos certa fragilidade nas respostas, pois, não conseguem apontar com clareza a importância dos estudos sobre os aspectos geográficos do RN, o que denota pouca experiência com o assunto em questão. Conforme investigamos, para P1e P3, a aproximação com a Geografia do RN aconteceu apenas durante a graduação; já P2, teve uma experiência maior, porque lecionou a disciplina Cultura do RN e Economia do RN, quando compunha a grade curricular no Ensino Médio, eliminadas do currículo em 2011. Fora isso, esses profissionais nunca tiveram uma experiência mais concreta com a Geografia do RN, nem mesmo através de capacitações ou cursos de pós-graduação.

Todavia, P3 demonstrou-se reflexivo quanto à pergunta, assumindo que de fato pouco se estuda sobre a Geografia do RN, reconhecendo também a pertinência do questionamento sobre algo que necessitaria no mínimo de uma boa reflexão. A pergunta despertou no professor um momento de reflexão, por isso, já avaliamos como um ponto positivo alcançado a partir da pesquisa. Porque acreditamos que é na reflexão da ação que a prática se efetiva.

A partir do momento em que os professores seguemapenas o livro didático, consequentemente, os conteúdos sobre a Geografia do RN perdem espaço, pois, os livros não discutem sobre a Geografia dos estados. Para possibilitar um lugar na disciplina, a abordagem sobre o RN exige um esforço para ir além do que está contido nos livros didáticos. Isso reflete na autonomia do ser professor, de se colocar como construtor do seu próprio currículo, contribuindo com o currículo escolar também. 0 educador precisa reconhecer que a utilização exclusiva do livro como referencial 
DOI: $10.12957 /$ e-mosaicos.2020.46572

teórico permite a abertura de lacunas no ensino, por isso, é necessário buscar caminhos viáveis que supram as deficiências que venham a surgir.

As entrevistas nos permitiram perceber que o RN só aparece na Geografia escolar a modo de contextualização e exemplificação de outros assuntos. Conforme destacou P3, na realidade o foco não é o RN. Dessa forma, compreendemos que a Geografia potiguar só aparece no contexto escolar por meio de atividades pontuais, entre as já mencionadas, identificamos também as aulas de campo.

As aulas de campo são um importante instrumento metodológico pela possibilidade de tornar a Geografia mais concreta e real, superando a superficialidade dos livros didáticos. Nesse sentido, o uso dessa metodologia por P1 e P2, constituem um ponto alto em que a Geografia do Rio Grande do Norte alcança notoriedade. Nos Quadros 04 e 05 estão sistematizados algumas aulas de campo realizadas por P1 e P2, com alunos do Ensino Médio.

Quadro 04: Aulas de campo realizadas por P1

\begin{tabular}{|c|c|l|}
\hline Turma & \multicolumn{1}{|c|}{ Local } & \multicolumn{1}{|c|}{ Conteúdo } \\
\hline $1^{\circ}$ ano & $\begin{array}{c}\text { Barragem de Santa Cruz; Lajedo de } \\
\text { Soledade - Apodi/RN }\end{array}$ & $\begin{array}{l}\text { Seca no Nordeste; Indústria da seca; } \\
\text { Reservatórios de água; Solo; Formações } \\
\text { rochosas. }\end{array}$ \\
\hline $2^{\circ}$ ano & $\begin{array}{c}\text { Rio Apodi Mossoró no bairro Manoel } \\
\text { Deodato - Pau dos Ferros/RN. }\end{array}$ & Hidrografia; Lixo; A importância do Rio. \\
\hline $3^{\circ}$ ano & $\begin{array}{c}\text { Lajedo de soledade - Apodi-RN / } \\
\text { Museu de Lampião e Shopping - } \\
\text { Mossoró/RN }\end{array}$ & $\begin{array}{l}\text { Formações geológicas; História do cangaço do } \\
\text { RN; Consumismo. }\end{array}$ \\
\hline
\end{tabular}

Fonte: Informações coletadas em dados da pesquisa de campo, 2017.

Quadro 05: Aulas de campo realizadas por P2

\begin{tabular}{|c|c|l|}
\hline Turma & Local & \multicolumn{1}{c|}{ Conteúdo } \\
\hline $1^{\circ}$ ano & Lajedo de soledade - Apodi/RN & $\begin{array}{l}\text { Formações geológicas; tipos de rochas; } \\
\text { processos erosivos; Degradação do ambiente. }\end{array}$ \\
\hline $1^{\circ}$ ano & Mina Brejuí - Currais Novos/RN & $\begin{array}{l}\text { Formações geológicas; tipos de rochas; a } \\
\text { economia local em torno do minério (sheelita); } \\
\text { História da mina. }\end{array}$ \\
\hline $3^{\circ}$ ano & $\begin{array}{c}\text { Comunidade Quilombola - } \\
\text { Portalegre/RN }\end{array}$ & $\begin{array}{l}\text { A formação e a diversidade cultural da } \\
\text { população brasileira: conhecer a história da } \\
\text { comunidade, a renda através da agricultura } \\
\text { familiar e da casa de farinha. }\end{array}$ \\
\hline
\end{tabular}

Fonte: Informações coletadas em dados da pesquisa de campo, 2017.

Temos que reconhecer que os trabalhos desses professores são muito valiosos para o entendimento da Geografia, além de contribuírem para dar visibilidade e valorização à Geografia potiguar. As aulas de campo parecem ser mínimas quando 
DOI: $10.12957 /$ e-mosaicos.2020.46572

comparadas ao tempo de docência desses profissionais. No entanto, não podemos desconsiderar que essas atividades são muito dispendiosas. Diante de muitas implicações, nesse tocante, podemos destacar algumas, a seguir.

Primeiro, porque esbarra na própria estrutura organizacional da escola, pois, é uma atividade que vai além dos muros da escola. Segundo, aumenta a responsabilidade e os cuidados que os professores têm, para os alunos menores de idade, e por último, é uma atividade que demanda custos, como: transporte, alimentação, dentre outros.

Como podemos perceber, apenas P3 não apresentou nenhuma aula de campo. No entanto, buscou justificar a razão da ausência dessa metodologia de ensino em sua prática docente. De acordo com o professor, o mesmo não se sente assegurado judicialmente sobre algo que possa vir a acontecer com seus alunos, durante a realização de uma aula de campo. Nesse sentido, prefere não arriscar; se limitando apenas à sala de aula. Mais uma vez, notamos que os obstáculos e desafios que surgem na ação são, muitas vezes, responsáveis por comprometer e até mesmo tornar inviável o desenvolvimento de uma aula dinâmica e instigadora.

Os alunos de P1 e P2 tiveram oportunidades e experiências concretas, que provavelmente os alunos de P3 nunca terão. Pode ser que os alunos de P3 já tenham visitado todos os lugares que os alunos de P1 e P2, conheceram através da aula de campo. Contudo, os alunos de P1 e P2 obtiveram um conhecimento mais aguçado sobre os lugares visitados, pois, foram instigados e orientados a explorar os aspectos geográficos, presentes naquele local. Enquanto que para os alunos de P3, a percepção não será a mesma.

As aulas de campo são realmente necessárias para o ensino de Geografia, e quando possível é importante que o professor faça uso desse recurso, pois, oportunizam para o ensino um momento prazeroso e oportuno para compreensão da realidade. Entretanto, existem entraves que comprometem o seu desenvolvimento, assim como P3 assinalou.

\section{Dificuldades PARA O ENSINO de CONTEÚdOS SObRe A GEOGRAFIA dO RN NO ENSINO MÉDIO}

Já notamos que as dificuldades fazem parte do processo educativo, e quando se trata de uma questão que envolve a autonomia do professor, sobre o que ensinar, torna-se ainda mais expressivo. Dessa forma, buscamos averiguar junto aos professores quais as dificuldades para abordar conteúdos sobre a Geografia do RN. No Quadro 06, estão apresentadas as principais dificuldades expressadas pelos professores. 
DOI: $10.12957 /$ e-mosaicos.2020.46572

Quadro 06: Dificuldades para ensinar conteúdos sobre a Geografia do RN

\begin{tabular}{|l|l|}
\hline Professor & \multicolumn{1}{|c|}{ Principais dificuldades } \\
\hline P 1 & $\begin{array}{l}\text { Nossa principal fonte é o livro didático, [...] Quando nós vamos trabalhar } \\
\text { esses conteúdos do Rio Grande do Norte, pesquisamos, pois, } \\
\text { infelizmente não tem material pra o professor trabalhar essa temática. } \\
\text { Nós que devemos pesquisar e montar todo o material. }\end{array}$ \\
\hline P 2 & $\begin{array}{l}\text { Os conteúdos sobre o RN são trabalhados esporadicamente. Eu acharia } \\
\text { mais interessante esse assunto no fundamental porque os alunos ainda } \\
\text { não têm preocupação com o Enem, [...] Mais a gente sabe que a nível } \\
\text { de Enem é uma coisa que não é tão importante, [...] Que é importante } \\
\text { é, mais pra o Enem já não é tanto, é bom ele saber, ele conhecer. [...] } \\
\text { Aí assim, o ensino da Geografia do Rio Grande do Norte já fica um pouco } \\
\text { de lado, existem assuntos mais urgentes, no sentido do Enem, a própria } \\
\text { escola exige isso. }\end{array}$ \\
\hline P 3 & $\begin{array}{l}\text { As maiores dificuldades seriam justamente tempo, precisaríamos de } \\
\text { tempo e precisaríamos também de recursos didáticos disponíveis, mapas } \\
\text { temáticos do RN, enfim, livros didáticos do próprio RN. A gente sabe que } \\
\text { a internet tem muita informação, mais informação nem sempre é ciência. } \\
\text { Então precisa de uma certa produção cientifica, já porque se trabalha } \\
\text { pouco ou nada da Geografia na sala de aula. }\end{array}$ \\
\hline
\end{tabular}

Fonte: Informações coletadas em dados da pesquisa de campo, 2017.

As principais dificuldades apresentadas pelos professores foram: ausência de material didático específico para discutir os conteúdos sobre a Geografia do RN em sala de aula e falta de tempo suficiente para introduzir novos conteúdos, em detrimento dos já determinados pelo livro didático. A inexistência de matérias que tratem com especificidade a Geografia norte-rio-grandense aparece nas respostas dos três professores. Uma vez que não têm material para trabalhar, a solução apontada por P1 é pesquisar na internet. Contudo, P3 coloca em questão o fato de que na internet tem muitas informações, mas que informação, por si só, não é ciência. P3 considera que a falta de material sobre os aspectos geográficos do RN acontece pelo fato de que pouco ou nada se trabalha sobre esses conteúdos no contexto escolar. 0 mesmo assinala que há a necessidade que haja produção científica nesta área temática.

Refletindo sobre o posicionamento desse professor, reconhecemos que na verdade não existe um livro didático específico sobre a Geografia do RN. No entanto, sabemos que existem nas bibliotecas, nos arquivos das Universidades, localizadas na região do Alto Oeste Potiguar, por exemplo, uma diversidade de trabalhos científicos riquíssimos, desenvolvidos por alunos, tanto de graduação, quanto de pós-graduação, que dão ênfase a diversos fenômenos que contemplam a Geografia do RN. A exemplo, citamos o livro Capítulos de Geografia do Rio Grande do Norte, organizado por Albano, 
DOI: $10.12957 / \mathrm{e}-\mathrm{mosaicos} .2020 .46572$

Ferreira e Alves (2014, 2015), que já está com seu II volume. Além de tantos outros trabalhos que podem oferecer uma importante contribuição teórica e prática para o ensino de Geografia, nessa perspectiva.

P2 leva-nos a pensar sobre uma problemática atual, fato que merece nossa atenção. Sugere que os conteúdos sobre o Rio Grande do Norte poderiam ser mais interessantes no currículo do Ensino Fundamental, porque no Ensino Médio os alunos estão mais centrados no Exame Nacional do Ensino Médio (ENEM). Entendemos com isso que no Ensino Médio existem conteúdos mais "urgentes" a nível de ENEM (contexto e conjuntura nacional), do que aqueles referentes ao território potiguar, por exemplo.

Desse modo, no que concerne à perspectiva do Rio Grande do Norte como conteúdo na Geografia escolar, podemos concluir que com essa nova forma de ingresso nas universidades, o estudo da Geografia dos estados torna-se cada vez mais obsoleto, em detrimento à preocupação de preparar o aluno para o ENEM.

Erramos quando não damos à Geografia o seu merecido papel, quando reduzimo-la à mera função de preparar cognitivamente o aluno apenas para um futuro ingresso na academia, e/ou mercado de trabalho. Estamos com isso, suprimindo o papel da Geografia, que deve buscar contribuir para uma compreensão do mundo e de suas complexidades, além de comprometer-se com a formação de um sujeito participativo, ativo e crítico.

\section{Os CONTEÚdos dA GEOGRAFIA dO RN: POR UMA GEOGRAFIA DA TOTALIDADE; E NÃO DA FRAGMENTAÇÃO}

É importante enfatizarmos que neste trabalho não propomos que haja uma fragmentação no ensino dos conteúdos da disciplina de Geografia, por meio de uma hierarquização dos conteúdos. Não estamos colocando o RN como uma dimensão de análise isolada e independente, mas, como uma realidade que foi e é construída historicamente pelo povo, pelos sujeitos sociohistóricos que constituem a sociedade.

O ensino de Geografia necessita fazer uma conexão com o próximo (local) e o, aparentemente, longínquo (global). Vencendo assim, o desafio da totalidade mundo, temática tão discutida por Straforini (2001), em Ensinar geografia nas séries iniciais: o desafio da totalidade mundo.

Conforme Santos (2006), a totalidade constitui um elemento fundamental para o conhecimento e análise da realidade, onde todas as coisas presentes no universo formam uma unidade. "A totalidade é o conjunto de todas as coisas e de todos os homens, em sua realidade, isto é, em suas relações, e em seu movimento" (SANTOS, 2006, p. 74).

Como escreve Straforini (2001), no atual momento histórico, marcado pela globalização, não há como conceber o mundo linearmente (casa, rua, bairro, cidade, 
DOI: $10.12957 / \mathrm{e}-\mathrm{mosaicos} .2020 .46572$

estado, país, continente), pois, o mundo não é a somatória dessas partes, mas sim, uma totalidade.

Assim, trazendo para o contexto desta pesquisa, percebemos que não podemos compreender a dinâmica do RN sem levar em consideração sua conexão com outros lugares. O território potiguar possui suas próprias particularidades, que, ao mesmo tempo, passam a ser compartilhadas com outros territórios, por meio das redes técnicas e informacionais.

O RN, por exemplo, se destaca como um grande produtor e exportador de melão do Brasil, que se concentra no Polo de Desenvolvimento Integrado AssúMossoró, cuja irrigação é feita pela captação de água de poços artesianos, dos Aquíferos Jandaíra e Açú, conforme podemos observar em Hespanhol (2015). A partir desse exemplo, percebemos que a economia do RN não está baseada apenas numa dinâmica local, mas que está relacionada a outros países(economia agroexportadora - commodities). Notamos neste exemplo, uma ligação do território potiguar com outros territórios e, respectivamente, outras economias. Assim, o RN necessita ser percebido em meio à totalidade-mundo, pois, não se configura como um ponto perdido no meio do mapa, uma vez que está direta ou indiretamente vinculado a outros territórios, culturas e economias.

Com base nos PCN, a Geografia no Ensino Médio tem a função de passar uma visão da totalidade, rompendo com a fragmentação dos conteúdos: Ao buscar compreender as relações econômicas, políticas, sociais e suas práticas nas escalas local, regional, nacional e global, a Geografia se concentra e contribui, na realidade para pensar o espaço enquanto uma totalidade na qual se passam todas as relações cotidianas e estabelecem as redes sociais nas referidas escalas.

Assim, o Estado do Rio Grande do Norte é uma manifestação da totalidade mundo. Configurado como uma porção do espaço, e objeto de estudo deste trabalho, apresenta-se como uma categoria analítica da totalidade, expressão utilizada em Santos (2012).

Desse modo, o RN visto como conteúdo escolar é uma parte dentro de um vasto campo de conhecimento que a Geografia estuda e que são essenciais para compreensão do espaço. Por isso, necessita estar vinculado à prática pedagógica dos professores de Geografia. Passando a ser abordado como conteúdo desta referida disciplina, pois, consideramos que o RN está submetido às influências locais e globais. O que faz dele também objeto de estudo da Geografia.

\section{CONSIDERAÇõES FINAIS}

As leituras indicaram poucas referências que deram fundamento à concepção do Rio Grande do Norte como conteúdo escolar. Isso mostra a necessidade de investir em pesquisas quem deem ênfase ao ensino de Geografia, e em particular aos conteúdos que contemplem uma leitura e compreensão dos aspectos geográficos, que 
DOI: $10.12957 /$ e-mosaicos.2020.46572

configuram os estados brasileiros. Esta reflexão é importante para que se torne cada vez mais possível a abordagem de conteúdos sobre o Rio Grande do Norte, no contexto escolar.

O livro didático é o principal recurso utilizado pelos professores, considerando o contexto das duas escolas aqui pesquisadas. No entanto, é importante ressaltar que, quando se dá preferência exclusiva ao livro didático, deixamos de dar visibilidade a outros conteúdos que não estão presentes nos livros, mas que são pertinentes para compreensão da totalidade do espaço, como é o caso dos conteúdos referentes à Geografia do Rio Grande do Norte.

Como foi possível observar, no decorrer deste trabalho, o RN só aparece nas discussões do Ensino Médio quando se trata de exemplificação ou contextualização dos conteúdos presentes no livro. Entretanto, identificamos como orientação metodológica à realização das aulas de campo, que, apesar de não serem muito frequentes, mostram a diversidade de riquezas que podem ser exploradas no referido estado, e que muitas vezes são desconhecidas pelos alunos.

Em síntese, podemos avaliar que a abordagem sobre o território potiguar, no ensino de Geografia, ainda é frágil e incipiente. E, se continuar dessa forma, as perspectivas são que se torne cada vez mais obsoletas, devido às escolas de Ensino Médio trabalharem com a meta de preparar os alunos para o Enem. Assim, como se trata de um exame nacional, a Geografia dos estados não se apresenta interessante para o estudo.

Compreendemos que preparar o aluno para um futuro ingresso acadêmico é uma função da escola. No entanto, isso não significa que a escola se reduza a esse único objetivo. Quando no ensino de Geografia deixamos minimizar o seu papel, corremos sérios riscos de repassar um conhecimento mecanizado, onde os alunos serão instruídos apenas para reproduzir o que ouvem, sem estímulo para desenvolver a capacidade de analisar, questionar, comparar e consequentemente, construir seu próprio conhecimento.

Quando olhamos para o ensino de Geografia, na atualidade, nos deparamos com uma realidade muitas vezes desmotivadora; os desafios e dificuldades são visíveis, assim como apontaram os professores sujeitos dessa pesquisa. Tudo isso são implicações que trazem limitações ao ensino.

Tantos foram os obstáculos que marcaram e ainda marcam a história da Geografia escolar no Brasil, mas, também não podemos nos esquecer das conquistas e avanços que já obtivemos através de muita luta, resistência e estudo. Por isso, precisamos renovar o nosso compromisso com a educação e formação dos sujeitos, pensando e fazendo uma Geografia capaz de romper com os ditames tradicionais ou políticas de acesso à universidade de modo generalista em termos nacionais, e que, por fim, que a valorização da formação em Geografia tenha significado para a vida. 
DOI: $10.12957 /$ e-mosaicos.2020.46572

\section{REFERÊNCIAS}

BRASIL. Ministério da Educação. Parâmetros Curriculares Nacionais (PCNs). Ciências Humanas e suas Tecnologias.Brasília: MEC, 2002.

FELIPE, José Lacerda Alves; RODRIGUEZ, Janete Lins. Atlas Escolares Estaduais: Um novo olhar para a educação e a pesquisa geográfica. In: ENCONTRO NACIONAL DE PRÁTICAS DE ENSINO EM GEOGRAFIA. 10., 2009, Porto Alegre. Anais [...]. Porto Alegre, Associação dos Geógrafos Brasileiros (AGB), 2009.

HESPANHOL, Antônio Nivaldo. A fruticultura irrigada no polo de desenvolvimento integrado Assu-Mossoró -Estado do Rio Grande do Norte - Brasil. In: Jornadas Interdisciplinarias de Estudios Agrarios y Agroindustriales Argentinos y Latinoamericanos, 9., 2015, Buenos Aires. Anais [...]. Buenos Aires, Universidade de Buenos Aires, 2015, p. 1-22. Disponível em:

http://www2.fct.unesp.br/nivaldo/Publica\%E7\%F5esnivaldo/2015/POLO\%20DE\%20 FRUTICULTURA\%20-\%20RN.pdf. Acesso em: 09 dez. 2016.

OLIVA, Jaime Tadeu. Ensino de Geografia: um retrato desnecessário. In: CARLOS, Ana Fani Alessandri(Org.).A Geografia na sala de aula. São Paulo: Editora Contexto, 2006, p.34-61.

OLIVEIRA, Ariovaldo Umbelino de. Educação e ensino de Geografia na realidade brasileira. In: OLIVEIRA, Ariovaldo Umbelino (Org.). Para onde vai o ensino de Geografia? 9 ed. São Paulo: Editora Contexto, 2008, p. 135-144.

RIO GRANDE DO NORTE. Constituição do Estado do Rio Grande do Norte. Natal: Assembleia Legislativa do Estado do Rio Grande do Norte, 1989.

SANTOS, Milton. A natureza do Espaço: Técnica e tempo, razão e emoção. 4 ed., São Paulo: Editora da Universidade de São Paulo, 2006.

SANTOS, Milton. Da Totalidade ao Lugar. São Paulo: Editora da Universidade de São Paulo, 2012.

STRAFORINI, Rafael. Ensinar geografia nas séries iniciais: O desafio da totalidade mundo. 2001. 150f. Dissertação. (Mestrado em Geociências) - Instituto de Geociências, Universidade Estadual de Campinas, Campinas, 2001. Disponível em: http://repositorio.unicamp.br/handle/REPOSIP/287405. Acesso em: 11 dez. 2016. 
DOI: $10.12957 / \mathrm{e}-\mathrm{mosaicos} .2020 .46572$

VESENTINI, José Willian. Para uma Geografia crítica na escola. São Paulo: Editora do Autor, 2008.

Recebido em 04 de novembro de 2019

Aceito em 22 de abril de 2020

A e-Mosaicos Revista Multidisciplinar de Ensino, Pesquisa, Extensão e Cultura do Instituto de Aplicação Fernando Rodrigues da Silveira (CAp-UERJ) está licenciada com uma Licença Creative Commons - Atribuição-NãoComercial 4.0 Internacional.

Os direitos autorais de todos os trabalhos publicados na revista pertencem ao(s) seu(s) autor(es) e coautor(es), com o direito de primeira publicação cedido à e-Mosaicos.

Os artigos publicados são de acesso público, de uso gratuito, com atribuição de autoria obrigatória, para aplicações de finalidade educacional e não-comercial, de acordo com o modelo de licenciamento Creative Commons adotado pela revista. 